\title{
Fundamentos para despenalizar la contaminación acústica en el Perú, 2015 - 2018
}

\author{
Foundations to decriminalize noise pollution in Peru, 2015 - 2018
}

Fundações para descriminalizar a poluição sonora no Peru, 2015-2018

\section{ARTÍCULO GENERAL}

\section{Guillermo Evaristo Medina Sanjinez gui_medsan@hotmail.com https://orcid.org/0000-0001-5821-0228}

Abogado por la Universidad San Pedro, Magister en Derecho Penal y Ciencias Criminológicas y estudios de doctorado en Derecho y Ciencias Políticas por la Universidad Nacional de Trujillo - Perú, estudios de doctorado en Derecho Penal y Procesal Penal por la Universidad de Sevilla - España, investigador visitante en el Max-Planck-Institut zur Erforschung von Kriminalität, Sicherheit und Recht, Freiburg im Breisgau-Alemania.

Recibido 07 de Abril 2021 | Arbitrado y aceptado 19 de Junio 2021 | Publicado en 03 Setiembre 2021

\section{RESUMEN}

El artículo 304 del Código Penal peruano, dentro de los supuestos típicos ha considerado como delito a la contaminación acústica, conducta que no cuenta con justificación suficiente para ser penalizada, considerando que no tiene relevancia penal. La presente investigación se justifica porque es un problema vigente en nuestra normativa penal que debe ser abordado para dar una solución con fundamentos dogmáticos; tiene como objetivo determinar cuáles son los fundamentos para despenalizar la contaminación acústica. Los métodos utilizados fueron hermenéutico y estadístico. Técnica aplicada, recopilación documental y encuesta aplicada. La muestra fue determinada por 380 abogados registrados en el Colegio de Abogados de Lima, mediante el muestreo estadístico probabilístico aleatorio. Se logró como resultado que los encuestados respondieron afirmativamente, que la ausencia de sentencias condenatorias, la aplicación del Derecho Penal de ultima ratio y la intervención del Derecho Administrativo Sancionador constituyen el fundamento para despenalizar la contaminación acústica. Concusión, existe ausencia de sentencias penales condenatorias por el delito de contaminación acústica, por ser una conducta que carece de relevancia penal, lo que justifica que el Derecho Administrativo Sancionador debe intervenir para que ejerza su potestad sancionadora.

Palabras claves: sentencias; ultima ratio; despenalizar.

\begin{abstract}
Article 304 of the Peruvian Penal Code, within the typical assumptions, has considered noise pollution a crime, conduct that does not have sufficient justification to be penalized, considering that it has no criminal relevance. The present investigation is justified because it is a current problem in our penal regulations that must be addressed to provide a solution with dogmatic foundations; aims to determine what are the grounds for decriminalizing noise pollution. The methods used were hermeneutical and statistical. Applied technique, documentary compilation and applied survey. The sample was determined by 380 lawyers registered with the Lima Bar Association, through random statistical probability sampling. As a result, it was achieved that the respondents answered affirmatively, that the absence of convictions, the application of the Ultima Ratio Criminal Law and the intervention of the Administrative Penalty Law constitute the basis for decriminalizing noise pollution. Concussion, there is an absence of criminal convictions for the crime of noise pollution, as it is a conduct that has no criminal relevance, which justifies that the Administrative Penalty Law must intervene in order for it to exercise its sanctioning power.
\end{abstract}

Keywords: sentences; last ratio; decriminalize.

\section{RESUMO}

O artigo 304 do Código Penal Peruano, dentro dos pressupostos típicos, considerou crime a poluição sonora, conduta que não tem justificativa suficiente para ser punida, por não ter relevância criminal. A presente investigação justifica-se por se tratar de um problema atual em nossos regulamentos penais que deve ser enfrentado para podermos encontrar uma solução com fundamentos dogmáticos; visa determinar quais são os fundamentos para descriminalizar a poluição sonora. Os métodos utilizados foram hermenêuticos e estatísticos. Técnica aplicada, compilação documental e levantamento aplicado. A amostra foi determinada por 380 advogados cadastrados na Ordem dos Advogados de Lima, por meio de amostragem estatística probabilística aleatória. Conseguiu-se como resultado que os inquiridos responderam afirmativamente que a ausência de condenação, a aplicação da Última Razão do Direito Penal e a intervenção do Direito Penal Administrativo constituem a base para a descriminalização da poluição sonora. Concussão, há ausência de condenação criminal pelo crime de poluição sonora, por se tratar de uma conduta sem relevância criminal, o que justifica que a Lei da Pena Administrativa deva intervir para que possa exercer o seu poder sancionador.

Palavras-chave: sentenças; última proporção; descriminalizar. 


\section{INTRODUCIÓN:}

En la actualidad en el Código Penal peruano se han venido extendiendo e incorporando nuevas conductas como delitos, por la ausencia de una política criminal, ya sea por simple populismo o por interés propio de los legisladores y en otras ocasiones por falta de conocimiento en las materias, donde algunas conductas justifican su tipificación y otras no, ya que en su gran mayoría la afectación a los derechos violentados no tiene relevancia penal.

Si bien es cierto, la contaminación acústica ha sido tipificada como delito, hecho que considero que no tiene una justificación suficiente, ya que existen otras disciplinas que podrían enfrentar el problema, pues, al parecer es el Derecho Penal quien está concebido para dar solución a la problemática de la sociedad; lo cual nos motivó a desarrollar la presente investigación, y nos ha permitido conocer que la contaminación acústica realmente debería ser enfrentada a través del procedimiento administrativo sancionador y no mediante un proceso penal.

La contaminación acústica es un problema que afecta al Perú, motivo por el cual sus impactos deben ser sancionados como infracciones administrativas por los gobiernos locales en cumplimiento de su potestad sancionadora conforme al Derecho Administrativo Sancionador.

El presente trabajo de investigación tiene una justificación teórica, en razón que se desarrollaron fundamentos teóricos y dogmáticos que permitieron sustentar de manera sólida, el por qué se debe despenalizar la contaminación acústica de nuestro Código Penal; tiene una justificación metodológica toda vez que con la aplicación de encuestas y análisis de los procesos penales de delitos de contaminación acústica, nos ha permitido comprobar la existencia de una regulación penal inadecuada; cuenta con una justificación práctica ya que despenalizando la contaminación acústica demostramos que no toda conducta que genera una afectación o perjuicio debe ser penalizada como delito; y una justificación jurídica, ya que gracias a su desarrollo se podrá crear una iniciativa legislativa para despenalizar la contaminación acústica descrita dentro de los supuestos típicos del artículo trescientos cuatro del Código Penal.

Pastor, (2005, p. 2 y ss.), concluye en su investigación que la afectación auditiva de la población del Centro Histórico de la ciudad de Trujillo que estuvo expuesta a ruidos, está relacionada con su intensidad; para, Alenza (2003, p. 65) el ruido debe entenderse como una forma de contaminación ambiental y, por ello, las normas jurídicas que luchan contra él constituyen un subsistema del Derecho Ambiental. Sampedro (2011.p. 14), considera 
que los delitos ambientales como la contaminación sonora, constituye un ilícito penal de peligro abstracto.

Rodríguez (2015, p. 20), afirma que el ruido ambiental constituye un peligro a la salud y la tranquilidad de la población y esto se origina por el incumplimiento de la normatividad administrativa y penalizar no sería la solución. Alanya et al. (2016, p. 2), concluyen que el ruido en ambientes urbanos tiene que ver con el orden territorial y la planificación urbanística, sumada con políticas contra la contaminación provocada por el ruido. García (2016, p.19), explica que el fenómeno del ruido ha estado siempre presente en la historia de los seres humanos, hasta hace poco ha sido considerado un factor contaminante, en las últimas décadas, el ruido ostenta un destacado papel en la vida pública de un país.

En el Perú los niveles permitidos para la emisión de sonidos o ruidos son muy altos a los que recomienda la OMS que son 55 y 40 decibeles en los horarios diurno y nocturno respectivamente para el ámbito exterior, en nuestra normativa nacional se han establecido parámetros en zonas residenciales en horario diurno 60 y nocturno 50 decibeles, pero muchas instituciones públicas (municipalidades provinciales y distritales), encargadas de normar los procedimientos, las conductas infractoras y sus respectivas sanciones por actos que generen contaminación acústica, aun no las han regulado.

La política criminal ha sido definida por varios especialistas, entre los que se encuentra Peña Cabrera (2013, p.71), para quien la política criminal está orientada para proteger bienes jurídicos dentro del marco de los intereses difusos. Por su parte Roxin (2013, p.73), indica que una política criminal debe respetar los derechos fundamentales que permitan el libre desarrollo del individuo y el funcionamiento de un sistema jurídico. En palabras de Hurtado (2005, p.59), la política criminal es una disciplina que tiene por finalidad estudiar la reacción contra la criminalidad.

Es importante señalar que la política criminal en el Perú, se encuentra en crisis, pues, el Estado no ha logrado llevar a cabo una política pública que se encuentre en relación directa con el observatorio de criminalidad, es decir, sin tomar en cuenta los datos de las ciudades se ha criminalizado la contaminación sonora; siendo el su único sustento que se encuentra regulado como delito en otros países.

Parte de la doctrina nacional, aceptan que la contaminación auditiva sea tipificada como delito, pero existe otro sector de la doctrina que no está de acuerdo y afirman que la actual política criminal ambiental sólo es simbólica.

Según Caro (2009) y La Madrid (2011), en el Perú la política criminal medio ambiental es ineficaz, toda vez que no permite una protección real al medio ambiente, la vida y la 
salud de las personas. Pues las políticas ambientales en el Perú, son solamente simbólicas, draconianas y represivas antes que preventivas.

Ahora trataremos un tema de suma importancia en esta investigación, es el referente a los fundamentos para despenalizar delitos contra el medio ambiente y de manera específica, la contaminación acústica. La despenalización ayudaría a resolver la problemática legislativa en materia penal, para nuestro caso de estudio el fortalecimiento del sistema sancionatorio dentro del marco constitucional menos represivo, para conseguir una justicia ideal, donde se respeten los derechos fundamentales.

Nos queda claro que uno de los problemas primordiales en la sociedad peruana es la ausencia de una política criminal y técnica legislativa; hecho que justifica la urgencia de la implementación de una política criminal de despenalización ambiental, la cual nos ayudará a resolver muchos de los problemas generados por la justicia penal deficiente que en la actualidad prima en el país.

El derecho comparado a través de su jurisprudencia, legislación y doctrina sobre la despenalización nos ilustran que vivimos en una sociedad moderna donde el Derecho Penal de primera ratio pasa a ser de ultima ratio, el cual es una respuesta a las nuevas exigencias de una sociedad dentro de un Estado democrático, donde se respetan los derechos fundamentales. La sociedad es cambiante; por ello, la despenalización del Derecho Penal es materia de todos los Estados modernos del cual el Perú es parte.

Hoy en día no podemos permanecer inertes ante los acontecimientos en las sociedades modernas el cual se refiere a la despenalización de conductas tipificadas como delitos en los Códigos Penales. Por tanto, tenemos que prepararnos si queremos contar con una administración de justicia que no afecte derechos fundamentales de los ciudadanos.

La despenalización en el Derecho Penal, debe diseñarse mediante una verdadera política pública que se ocupe de todos los recursos del Estado, donde se tengan acceso a datos estadísticos de sentencias en los procesos judiciales y del resultado de los procedimientos sancionadores tramitados en los Gobiernos Regionales, Municipalidades y del Ministerio del Ambiente.

Así para Barba $(2008$, p. 81), al referirse a la despenalización señala que se viene excediendo del uso del Derecho Penal reprimiendo conductas inofensivas, donde fruto de reformas llegan a criminalizar hechos de escaso valor como la contaminación auditiva. El legislador actúa de manera populista permitiendo una positivización de delitos que en realidad no lo son, como cuando se tipifica como delito a la contaminación auditiva. 
La despenalización funciona más allá de sus límites permitiendo la existencia de otros subsistemas como el Derecho Administrativo Sancionador, el principio de mínima intervención, y la no criminalización injusta. Hay que tomar en cuenta también, que cuando existen problemas en el poder punitivo administrativo, despenalizar conductas también sería un problema, pero se requiere de un desafío, caso contrario seguiremos con una justicia lenta, la estictimatización de las personas y prisiones hacinadas.

Así, para Carnevali (2008, p.18) "el principio de última ratio constituye un límite esencial al poder punitivo del Estado". En palabras de Monroy (2013, p. 25), el Derecho Penal de última ratio no permite sancionar cuando existe otros medios para la protección de la convivencia social. Por su parte Martínez (2015, p. 34) afirma que la protección del medio ambiente a través del Derecho Penal debe efectuarse de manera subsidiaria y accesoria al Derecho Administrativo Sancionador. Para López (2015, p. 20), el principio de lesividad establece que las conductas consideradas como delitos cuya capacidad ofensiva sea mínima, no deben ser considerados como delitos, tal es el caso de la contaminación auditiva.

La investigación fija su interés ante la vigencia del artículo trecientos cuatro del Código Penal peruano, que tipifica los delitos contra el medio ambiente, donde también se incluye la contaminación acústica, conducta que debe ser despenalizada, en razón que no tiene relevancia penal, ya que la afectación o puesta en peligro de los derechos no es tan grave en comparación a otras conductas típicas. El legislador peruano no debería mantener esta modalidad delictiva en particular como una forma de sancionar las conductas que atentan el medio ambiente; ya que, es más apropiado optar por una sistemática distinta, establecida conforme al Derecho Administrativo Sancionador, es decir, postulamos por despenalizar la contaminación producida por los ruidos.

En este orden de ideas el Derecho Administrativo Sancionador debe desempeñar un rol muy importante para que cumpla la función de prevención, realizando acciones de control, fiscalización y sanción, a través de los órganos de la administración pública, sea Gobiernos Regionales, Municipalidades o el Ministerio del Ambiente, con lo cual sería innecesaria la tipificación del delito de contaminación acústica.

El Derecho Administrativo Sancionador ha sido desarrollado y fundamentado por varios especialistas, entre los que se encuentra Cordero (2012, p. 132) para quien, indica que el poder punitivo de la administración cuenta con principios, procedimientos y aspecto sustantivo, que tienen fundamento constitucional. 
La doctrina autorizada establece que la potestad para sancionar de un estado se efectúa a través del Derecho Administrativo Sancionador y el Derecho Penal. Por ello, los principios de tipicidad, culpabilidad y legalidad, son principios del Derecho Sancionador aplicables al Derecho Administrativo Sancionador y al Derecho Penal.

De acuerdo a nuestra investigación, en el Perú en el período 2015-2018 se presentaron 322 denuncias penales ante las fiscalías provinciales penales por el delito de contaminación acústica. Los datos obtenidos fueron fruto del trabajo de campo llevado a cabo por nuestra parte. De los cuales tuvieron méritos a formalizar denuncias solamente 40 casos, registrado en las Cortes Superiores de Justicia del Perú, hasta el momento en este período de estudio sólo existen cinco condenas en primera instancia, todas revocadas en las Salas Superiores y la Corte Suprema en sus casaciones, donde se ha dispuesto que se lleve a cabo nuevos juicios sin entrar en el fondo del problema para determinar si nos encontramos frente a un ilícito administrativo o ilícito penal, el cual es una labor que le compete para fijar reglas que le permitan a los juzgados de menor jerarquía resolver con mejores criterios.

Debemos señalar que en el período de estudio de esta investigación no existió una sola sentencia condenatoria firme por el delito de contaminación acústica, el cual a todas luces convierte al supuesto típico de contaminación acústica descrito en el artículo antes mencionado, en ineficaz y que para algunos lo consideran como un Derecho Penal Simbólico, opinión que no compartimos.

Para nuestra investigación es conveniente evaluar la Casación 762-2017, Arequipa. De acuerdo con esta Casación, los delitos contra el medio ambiente previstos en el artículo trecientos cuatro del Código Penal peruano, deben ser complementados con normativa extrapenal. En la actualidad en el Perú la norma especial que regula los límites máximos permitidos de ruidos en el medio ambiente, es el Reglamento de Estándares de Calidad Ambiental para el Ruido.

Considero, que la comisión de un ilícito administrativo y la respectiva sanción administrativa debe ser de acuerdo a la gravedad del caso, desde la imposición de una multa hasta la clausura definitiva de la entidad contaminadora, ciertamente en este supuesto en la Casación no se ha puesto nuestra Corte Suprema, pues no entra a analizar los límites entre ilícito penal e ilícito administrativo; problemática de vital importancia, pues entiende que la penalización de la contaminación auditiva va de acorde con la realidad. 
Los delitos contra el medio ambiente son considerados como delitos de resultado, no consumándose con el quebrantamiento de la normativa administrativa, sino que además se requiere de la existencia de un perjuicio o daño grave, esta es la posición que ha adoptado la Corte Suprema. De esto se desprende que la gravedad del resultado, sólo es causado por sonidos graves e intensos y que estos lesionen o pongan en peligro de manera grave los derechos tutelados.

Respetuosamente discrepo con la Corte Suprema; puesto que, si se atentara contra la salud y la vida en la modalidad de lesiones como consecuencia de la contaminación acústica, para ello el Código Penal ha previsto con amplitud los supuestos de comisión de estos delitos y su forma de solucionarlos. La Corte Suprema debe sentar posición respecto a que los niveles de ruidos permisibles y los estándares de calidad ambiental para el ruido son dos regulaciones diferentes, equipararlos es jurídicamente imposible.

A nuestro juicio la presente casación, en vez de fijar grandes líneas jurisprudenciales dejan grandes preguntas, entre ellas la necesidad de delimitar entre el ilícito administrativo del ilícito penal.

En la presente investigación se planteó como interrogante la siguiente:

¿Cuáles son los fundamentos para despenalizar la contaminación acústica en el Perú establecida en el artículo 304 del Código Penal, 2015 - 2018? Se consideró como objetivo principal, determinar los fundamentos para despenalizar el delito de contaminación acústica en el Perú. La hipótesis, los fundamentos para despenalizar la contaminación acústica son la ausencia de sentencias condenatorias, aplicación Derecho Penal de ultima ratio y la intervención del Derecho Administrativo Sancionador.

\section{MATERIALES Y MÉTODOS}

\subsection{El objeto de estudio}

Es la despenalización de la contaminación acústica establecida dentro de las conductas descritas en el artículo trecientos cuatro del Código Penal peruano.

\subsection{Población}

Constituida por 43,700 abogados datos proporcionados por el Colegio de Abogados de Lima durante los años 2015-2018.

\subsection{Muestra}

380 abogados incorporados en el Colegio de Abogados de Lima entre ellos se encuentran jueces, fiscales, profesores de Derecho Penal, funcionarios abogados de los Gobiernos 
Locales, funcionarios abogados del Ministerio del Ambiente, a quienes se les aplicó encuestas.

\subsection{Unidad de análisis}

El abogado incorporado en el Colegio de Abogados de Lima, quien respondió la encuesta efectuada.

\subsection{Diseño de la muestra}

No experimental, ya que no se manipulará ninguna variable.

El nivel de confiabilidad que se trabajará; donde $Z=1.96$ en un $95 \%$ de confianza o $Z=$ 1.65 en un $90 \%$ de confianza.

La forma de distribución de las características de la muestra en relación con las variables: Variable independiente: La ausencia de sentencias penales condenatorias, Derecho Penal de ultima ratio, Derecho Administrativo Sancionador.

Variable dependiente: Despenalización del delito de contaminación acústica.

Utilizaremos la fórmula con $95 \%$ de confianza, lo cual genera margen de error de un 5\% (0.05).

2.6. Métodos de investigación utilizados: método correlacional, método inductivo, método comparativo y hermenéutico jurídico.

2.7. Técnicas: documentales: recopilación documental, fichaje, técnicas personales, análisis metodológico, encuesta aplicada.

\subsection{Diseño de la investigación:}

Descriptiva y explicativa, porque se usó una muestra para observar y estudiar el impacto de los delitos de contaminación acústica.

El diseño de una sola casilla: ya que seleccionamos la muestra de la realidad problemática que se va a investigar.

Dónde:

Y Z

Y: La hipótesis es: Ausencia de sentencias condenatorias, aplicación del Derecho Penal de ultima ratio y la intervención del Derecho Administrativo Sancionador.

$\mathrm{Z}$ : Impacto para la despenalización del delito de contaminación acústica.

\section{RESULTADOS:}

Los encuestados se distribuyeron de la siguiente manera: 


\begin{tabular}{|l|l|}
\hline \multicolumn{1}{|c|}{ INSTITUCIÓN } & MUESTRA \\
\hline Jueces & 50 \\
\hline Fiscales & 50 \\
\hline Profesores de Derecho Penal & 80 \\
\hline $\begin{array}{l}\text { Funcionarios de Gobiernos Locales } \\
\text { (abogados) }\end{array}$ & 100 \\
\hline $\begin{array}{l}\text { Funcionarios del Ministerio del } \\
\text { Ambiente (abogados) }\end{array}$ & 100 \\
\hline TOTAL & 380 \\
\hline
\end{tabular}

Los cuadros, que incluyen cada pregunta relacionada con la investigación, quedaron como sigue:

\section{CUADRO No1}

¿Cree usted que la ausencia de sentencias condenatorias por contaminación acústica influye en su despenalización?

\begin{tabular}{|c|c|c|c|c|c|c|c|c|c|c|}
\hline \multirow[t]{3}{*}{ RESPUESTA } & \multicolumn{10}{|c|}{ MUESTRA } \\
\hline & \multicolumn{2}{|c|}{ Jueces } & \multicolumn{2}{|c|}{ Fiscales } & \multicolumn{2}{|c|}{$\begin{array}{ll}\text { Docentes de } \\
\text { Derecho Penal }\end{array}$} & \multicolumn{2}{|c|}{$\begin{array}{l}\text { Funcionarios } \\
\text { de los } \\
\text { Gobierno } \\
\text { Local }\end{array}$} & \multicolumn{2}{|c|}{$\begin{array}{l}\text { Funcionarios } \\
\text { del } \\
\text { Ministerio } \\
\text { del } \\
\text { Ambiente }\end{array}$} \\
\hline & $\mathrm{N}^{\mathrm{o}}$ & $\%$ & $\mathrm{~N}^{\mathrm{o}}$ & $\%$ & $\mathrm{~N}^{\mathrm{o}}$ & $\%$ & $\mathrm{~N}^{\mathrm{o}}$ & $\%$ & $\mathrm{~N}^{\mathrm{o}}$ & $\%$ \\
\hline Acertada & 40 & 80 & 40 & 80 & 72 & 90 & 70 & 70 & 70 & 70 \\
\hline Desacertada & 10 & 20 & 10 & 20 & 8 & 10 & 30 & 30 & 30 & 30 \\
\hline No sabe & 00 & $0 \mathrm{o}$ & 00 & 00 & 00 & 00 & 00 & 00 & 00 & 00 \\
\hline TOTAL & 50 & 100 & 50 & 100 & 80 & 100 & 100 & 100 & 100 & 100 \\
\hline
\end{tabular}

El Cuadro $N^{o} 1$, que planteó la interrogante: ¿Cree usted que la ausencia de sentencias condenatorias por contaminación acústica influye en su despenalización?, esta pregunta nos permitió obtener respuestas atinadas como era lógico esperar en jueces, fiscales y 
profesores de Derecho Penal. De esta manera, acertaron en un $80 \%$ los jueces y fiscales, mientras que en el caso de los profesores de Derecho Penal fue de 90\%. Debe destacarse que hay un porcentaje considerable de desconocimiento por parte de los funcionarios abogado de los Gobiernos Locales y Ministerio del Ambiente; pues, sólo acertaron en un $70 \%$, lo cual pone en evidencia que aún existe desconocimiento sobre la despenalización del Derecho Penal.

\section{CUADRO No2}

¿Considera Ud. que la aplicación del Derecho Penal de última ratio influye en la despenalización del delito contaminación acústica?

\begin{tabular}{|c|c|c|c|c|c|c|c|c|c|c|}
\hline \multirow[t]{3}{*}{ RESPUESTA } & \multicolumn{10}{|c|}{ MUESTRA } \\
\hline & \multicolumn{2}{|c|}{\begin{tabular}{|l|} 
Jueces \\
\end{tabular}} & \multicolumn{2}{|c|}{ Fiscales } & \multicolumn{2}{|c|}{$\begin{array}{l}\text { Profesores de } \\
\text { Derecho Penal }\end{array}$} & \multicolumn{2}{|c|}{$\begin{array}{l}\text { Funcionarios } \\
\text { de Gobiernos } \\
\text { Locales - } \\
\text { Abogados }\end{array}$} & \multicolumn{2}{|c|}{$\begin{array}{l}\text { Funcionarios } \\
\text { del Ministerio } \\
\text { del Ambiente - } \\
\text { abogados }\end{array}$} \\
\hline & $\mathrm{N}^{\mathrm{o}}$ & $\%$ & $\mathrm{~N}^{\mathrm{o}}$ & $\%$ & $\mathrm{~N}^{\mathrm{o}}$ & $\%$ & $\mathrm{~N}^{\mathrm{o}}$ & $\%$ & $\mathrm{~N}^{\mathrm{o}}$ & $\%$ \\
\hline Acertada & 50 & 100 & 50 & 100 & 80 & 100 & 100 & 100 & 100 & 100 \\
\hline Desacertada & 00 & 00 & 00 & 00 & 00 & 00 & 00 & 00 & 00 & 00 \\
\hline No sabe & 00 & 00 & 00 & 00 & 00 & 00 & 00 & 00 & 00 & 00 \\
\hline TOTAL & 50 & 100 & 50 & 100 & 80 & 100 & 100 & 100 & 100 & 100 \\
\hline
\end{tabular}

Respecto al Cuadro $\mathbf{N}^{\mathbf{0}}$ 2, sobre la pregunta ¿Considera Ud. que la aplicación del Derecho Penal de última ratio influye en la despenalización del delito contaminación acústica?, Las respuestas en este caso fueron unánimes al $100 \%$ de los jueces, fiscales, profesores de Derecho Penal, funcionarios de Gobiernos Locales y funcionarios del Ministerio del Ambiente, quienes afirmaron estar de acuerdo con el Derecho Penal de última ratio, pues en una sociedad moderna ya no es posible seguir con los métodos tradicionales de aplicación de la pena.

\section{CUADRO N03}

¿Considera Ud. que la aplicación del Derecho Administrativo Sancionador influye en la despenalización del delito contaminación acústica? 


\begin{tabular}{|c|c|c|c|c|c|c|c|c|c|c|}
\hline \multirow[t]{3}{*}{ RESPUESTA } & \multicolumn{10}{|c|}{ MUESTRA } \\
\hline & \multicolumn{2}{|c|}{ Jueces } & \multicolumn{2}{|c|}{ Fiscales } & \multicolumn{2}{|c|}{$\begin{array}{l}\text { Profesores de } \\
\text { Derecho Penal }\end{array}$} & \multicolumn{2}{|c|}{\begin{tabular}{|l} 
Funcionarios de \\
Gobiernos \\
Locales \\
abogados
\end{tabular}} & \multicolumn{2}{|c|}{$\begin{array}{l}\text { Funcionarios } \\
\text { del Ministerio } \\
\text { del Ambiente - } \\
\text { abogados }\end{array}$} \\
\hline & $\mathrm{N}^{\mathrm{o}}$ & $\%$ & $\mathrm{~N}^{\mathrm{o}}$ & $\%$ & $\mathrm{~N}^{\mathrm{o}}$ & $\%$ & $\mathrm{~N}^{\mathrm{o}}$ & $\%$ & $\mathrm{~N}^{\mathrm{o}}$ & $\%$ \\
\hline De acuerdo & 50 & 100 & 50 & 100 & 80 & 100 & 80 & 100 & 70 & 70 \\
\hline En desacuerdo & 00 & 00 & 00 & 00 & 00 & 00 & 00 & 00 & 30 & 30 \\
\hline No conoce & 00 & 00 & 00 & 00 & 00 & 00 & 00 & 00 & 00 & 00 \\
\hline TOTAL & 50 & 100 & 50 & 100 & 80 & 100 & 100 & 100 & 100 & 100 \\
\hline
\end{tabular}

Respecto al Cuadro $\mathbf{N}^{\mathbf{3}} 3$ ¿Considera Ud. que la aplicación del Derecho Administrativo Sancionador influye en la despenalización del delito contaminación acústica?, En referencia a esta pregunta respondieron estar de acuerdo a esta interrogante tanto jueces, fiscales, profesores de Derecho Penal y funcionarios de Gobiernos Locales y solo un 30\% de funcionarios del Ministerio del Ambiente estuvieron en desacuerdo, lo cual no es muy significativo. Explicaron tanto los funcionarios abogados del Ministerio del Ambiente y los Municipios, que cumplen con su labor que la ley les permite, pues no otorgan licencias para el funcionamiento de locales comerciales, discotecas, fábricas en lugares que no son adecuados.

\section{CUADR0 N04}

¿La Casación 762-2017, Arequipa; donde se pronuncia sobre el delito de contaminación acústica, siendo la jurisprudencia vinculante actual debería cambiar?

\begin{tabular}{|c|c|c|c|c|c|c|c|c|c|c|}
\hline \multirow{3}{*}{ RESPUESTA } & \multicolumn{10}{|c|}{ MUESTRA } \\
\hline & \multicolumn{2}{|c|}{ Jueces } & \multicolumn{2}{|c|}{ Fiscales } & \multicolumn{2}{|c|}{$\begin{array}{l}\text { Profesores de } \\
\text { Derecho Penal }\end{array}$} & \multicolumn{2}{|c|}{$\begin{array}{l}\text { Funcionarios } \\
\text { de Gobiernos } \\
\text { Locales }\end{array}$} & \multicolumn{2}{|c|}{$\begin{array}{l}\text { Funcionarios } \\
\text { del Ministerio } \\
\text { del Ambiente }\end{array}$} \\
\hline & $\mathrm{N}^{\mathrm{o}}$ & $\%$ & $\mathrm{~N}^{\mathrm{o}}$ & $\%$ & $\mathrm{~N}^{\mathrm{o}}$ & $\%$ & $\mathrm{~N}^{\mathrm{o}}$ & $\%$ & $\mathrm{~N}^{\mathrm{o}}$ & $\%$ \\
\hline
\end{tabular}




\begin{tabular}{|l|l|l|l|l|l|l|l|l|l|l|}
\hline Positiva & 50 & 100 & 50 & 100 & 80 & 100 & 100 & 100 & 100 & 100 \\
\hline Negativa & 00 & 00 & 00 & 00 & 00 & 00 & 00 & 00 & 00 & 00 \\
\hline No sabe & 00 & 00 & 00 & 00 & 00 & 00 & 00 & 00 & 00 & 00 \\
\hline TOTAL & 50 & 100 & 50 & 100 & 80 & 100 & 100 & 100 & 100 & 100 \\
\hline
\end{tabular}

Respecto al cuadro $\mathbf{N}^{\circ}$ 04; referente a la pregunta ¿La Casación 762-2017, Arequipa; donde se pronuncia sobre el delito de contaminación acústica, siendo la jurisprudencia vinculatoria actual debería cambiar?, la respuesta de los entrevistados fue uniforme, pues afirman que si se debería cambiar la Casación, pues trae considerandos que no se ajustan a la realidad, debió declarar infundada la casación pues no existía mérito para un nuevo juicio, toda vez estamos frente a una problemática de infracciones administrativas y no delictivas.

\section{CUADRO $N^{\circ} 5$}

Correlación entre la ausencia de sentencias penales condenatorias y la despenalización del delito de contaminación acústica

\begin{tabular}{|l|l|l|}
\hline $\begin{array}{l}\text { AUSENCIA DE SENTENCIAS } \\
\text { PENALES CONDENATORIAS Y } \\
\text { EL DELITO CONTAMINACIÓN } \\
\text { ACÚSTICA }\end{array}$ & Rho & DESPENALIZACION \\
\hline $\begin{array}{l}\text { Legislación penal sin legitimidad } \\
\text { Necesidad de despenalización }\end{array}$ & 29 & -147 \\
\hline $\begin{array}{l}\text { Comportamiento de los funcionarios } \\
\text { de Gobiernos Locales y de Ministerio } \\
\text { del Ambiente }\end{array}$ & -121 & 206 \\
\hline El acceso a los tribunales & -188 & 194 \\
\hline
\end{tabular}

La ausencia de sentencias penales condenatoria muestra una mayor tendencia hacia la despenalización del delito de contaminación acústica. 


\section{DISCUCIÓN}

En la contrastación de hipótesis se ha de demostrado su validez: la ausencia de sentencias condenatorias, aplicación del Derecho Penal de ultima ratio y la intervención del Derecho Administrativo Sancionador constituyen el fundamento para despenalizar la contaminación acústica establecida en el artículo trescientos cuatro del Código Penal.

Se observa, que el Chi cuadrado es mayor a 1; por lo que, podemos interpretar que, a mayor ausencia de sentencias condenatorias, aplicación del Derecho Penal de ultima ratio y la intervención del Derecho Administrativo Sancionador permitirá despenalizar la contaminación acústica establecido dentro de los supuestos típicos del artículo trescientos cuatro del Código Penal peruano. Se acepta la hipótesis planteada a un grado de $95 \%$ de significancia, con un 5\% de margen de error.

\section{Regulación del delito de contaminación acústica en el Perú}

El Código Penal peruano en su artículo trecientos cuatro, tipifica los delitos ambientales, en el que se incluye la contaminación acústica, esta conducta debe ser despenalizada, en razón que no tiene relevancia penal, ya que la afectación o puesta en peligro de los derechos no es tan grave en comparación a otras conductas típicas. El legislador peruano no debería mantener esta modalidad delictiva en particular como una forma de sancionar las conductas que atentan al medio ambiente; ya que, es más apropiado optar por una sistemática distinta, establecida conforme al Derecho Administrativo Sancionador, es decir, postulamos por despenalizar la contaminación producida por los ruidos.

\section{EI Poder Judicial en materia de delitos de contaminación acústica en el Perú}

A nuestro juicio, en la Casación 762-2017, Arequipa, se ha determinado que los delitos contra el medio ambiente previstos en el artículo trecientos cuatro del Código Penal peruano deben ser complementados con normativa extrapenal; es por ello, que constituye ley penal en blanco.

En la actualidad en nuestro país, gran cantidad de Municipios no han regulado los límites permisibles para el ruido. De ello se desprende que la norma general aplicable es el Reglamento de Estándares Nacionales de Calidad Ambiental para el Ruido, quien determina los niveles máximos permitidos de contaminación por ruido. Siendo el objetivo principal el de conservar la calidad ambiental con el uso de la tecnología. Otro aspecto fundamental es que nuestra legislación punitiva define que los delitos contra el medio ambiente son delitos resultado; no consumándose con la sola vulneración de la norma 
administrativa, por lo que, requiere grave daño o perjuicio. Siendo esta la posición que ha adoptado nuestra Corte Suprema.

Pues, si como consecuencia de la contaminación acústica se afectara contra la salud, la vida en la modalidad de lesiones, para ello el Código Penal ha previsto con amplitud los supuestos de comisión de estos delitos.

\section{CONCLUSIONES}

- Se demostró que existe ausencia de sentencias penales condenatorias por contaminación acústica, por ser una conducta que carece de relevancia penal, lo que justifica que el Derecho Administrativo Sancionador debe intervenir para que ejerza su potestad sancionadora.

- Se determinó que existió una política criminal deficiente en la tipificación del delito de contaminación acústica prevista en el artículo trecientos cuatro del Código Penal peruano.

- Se demostró que el Derecho Penal debe intervenir como última ratio y únicamente cuando la afectación a los derechos sea grave y de relevancia, para lo cual se debe aplicar los principios intervención mínima, lesividad y fragmentariedad.

\section{REFERENCIAS BIBLIOGRÁFICAS}

\section{Revista}

Alenza J. 2003. La nueva estrategia contra la contaminación acústica y el ruido ambiental. Revista Jurídica de Navarra. Núm. 36: 65-120.

Barba, R. 2008. Política de despenalización como medio eficaz para una justicia penal justa. Revista Prolegómenos. Universidad Militar de Nueva Granada. Vol. 11. Núm. 21: 81-88.

DOI: https://doi.org/10.18359/prole.2526.

Caro, D. 2009. ¿Más penas para las empresas que contaminan?, en Revista Lawyer. Lima. Núm. 05: 71.

Cordero, E. 2012. E1 Derecho administrativo sancionador y su relación con el Derecho penal, en Revista de Derecho de la Universidad de Valdivia. Vol. XXV. Núm. 2: 131157. 
Jerico, L. 2016. Análisis de la relevancia penal de la contaminación acústica en ámbitos urbanos tras la reforma de los delitos contra el medio ambiente (LO 1/2015, de 30 de marzo). Revista Electrónica de Ciencia Penal y Criminología. Núm. 18-12: 1-34.

Martínez, J. 2015. "El principio de intervención mínima o última ratio en los delitos sobre la ordenación del territorio y el urbanismo". Revista del sector inmobiliario. Núm. 150: 34-38.

Peña Cabrera, A. 2013. Los delitos ambientales. Justicia \& Democracia, Revista de la Academia de la Magistratura. Lima, Núm. 11: 51-73.

Rodríguez, F. 2015. Ruido ambiental, comunicación y normatividad en la Ciudad de México. Razón y Palabra. Vol. 19. Núm. 91: 1-22.

\section{Libros}

Hurtado, J. 2005. Manual de Derecho Penal. Parte general, 3ra. Edición. Editorial Grijley, Lima, 2005. 1087 pp.

Lamadrid, A. 2011. Derecho penal ambiental en el Perú: ¿realidad concreta o simbolismo práctico? Editorial Grijley, Lima. 510 pp.

\section{Internet}

Alanya V, García, C y Patiño, K. 2016. El artículo $304^{\circ}$ del Código Penal y su incidencia en las sanciones penales por la Comisión del delito de contaminación ambiental en la Provincia de Coronel Portillo, período 2014. Tesis para optar el título de abogado. Facultad de Derecho y Ciencias Política de la Universidad Nacional de Ucayali. Pucallpa. Disponible en: http://repositorio.unu.edu.pe/bitstream/handle/UNU/3268/000002618T.pdf?sequence=1 \&isAllowed $=\mathrm{y}$.

García, A. 2016. El ruido: morfología medioambiental desde una perspectiva penal y criminológica. Tesis para optar el grado de Doctor en Derecho. Universidad Complutense de Madrid. Madrid. Disponible en: https://eprints.ucm.es/35309/1/T36776.pdf.

López, A. 2015. Análisis sobre el merecimiento y necesidad de pena en los delitos ambientales: a propósito del delito de contaminación ambiental. Tesis para optar el título de Abogado. Universidad de Piura. Facultad de Derecho, Programa Académico de Derecho. Piura. Disponible en: https://pirhua.udep.edu.pe/bitstream/handle/11042/2683/DER_032.pdf?sequence=1\&is Allowed $=\mathrm{y}$.

Monroy, A. 2013. “Principio de mínima intervención, ¿retórica o realidad?”. Derecho y Realidad. Núm. 21. Facultad de Derecho y Ciencias Sociales. Universidad Pedagógica y 
Tecnológica

de

Colombia.

Disponible

en:

https://revistas.uptc.edu.co/index.php/derecho_realidad/article/view/4827.

Pastor, J. 2005. Efectos de la contaminación acústica sobre la capacidad auditiva de los pobladores de la ciudad de Trujillo - Perú. Tesis para optar el grado de Doctor en Medio Ambiente. Escuela de Post Grado de la Universidad Nacional de Trujillo. Trujillo. Disponible en: http://dspace.unitru.edu.pe/handle/UNITRU/6005?show=full.

Roxin. C. 2013. El concepto de bien-jurídico como elemento de crítica legislativa sometido a examen. RECPC. Disponible en: http.ficriminetugnes/recpc/154cepc1501.pdf.

Sanpedro, P. 2011. El delito de contaminación acústica. La respuesta penal frente al ruido. Universidad Nacional de Educación a Distancia. Madrid. Disponible en: https://www2.uned.es/catortosa/Biblioteca_Digital/Biblio/Paloma_Sampedro/El\%20delito.pdf. 